\title{
The Gutless Marine Oligochaete Phallodrilus leukodermatus. Structural Studies on an Aberrant Tubificid Associated with Bacteria
}

\author{
Olav Giere \\ Zoologisches Institut und Museum, Universität Hamburg, Martin-Luther-King-Platz 3, D-2000 Hamburg 13, Federal Republic \\ of Germany
}

\begin{abstract}
Studies on anatomy and ultrastructure of the gutless tubificid Phallodrilus leukodermatus (Oligochaeta, Annelida) revealed the complete absence of intestinal tissues. However the wide, septate coelomic cavity is traversed by alveolate (mesodermal?) cells between which are embedded few longitudinal or oblique muscle strands and some blood vessels. The much wrinkled cuticle is densely stud with 'epicuticular projections' (Richards, 1977). In a space system between epidermis and cuticle, particularly wide in the postclitellar region, many gram-negative, rod-shaped bacteria are found. In the posterior part of the worms body numerous large, multivesiculate, membrane-bound corpuscles which lack typical cell organelles, fill the extra-epidermal subcuticular cavities. It is speculated that the bacteria, found in every specimen examined, are of nutritional significance for the worms. The aberrant anatomy of the tubificids, their association with procaryotes and parallels to other gutless marine animals are discussed
\end{abstract}

\section{INTRODUCTION}

A current interdisciplinary research project studies the gutless marine tubificid Phallodrilus leukodermatus, described by Giere (1979) from Bermudian coralline sands. The project comprises anatomical, ecological and (bio-)chemical aspects. This first paper summarizes some structural features of these aberrant oligochaetes.

\section{MATERIAL AND METHODS}

Phallodrilus leukodermatus, SCUBA collected at $\approx 4$ $\mathrm{m}$ water depth in the top $10 \mathrm{~cm}$ of calcareous sands in Bermuda, were fixed for electron microscopy (TEM, SEM) in $2,5 \%$ glutaraldehyde, buffered in $0,05 \mathrm{~m}$ phosphate buffer (Sörensen) and postfixed in 1\% osmiumtetroxide. For light-microscopy, the fresh material was treated with Worcester's fixative and sectioned ( $3 \mu \mathrm{m}$, Paraplast, stains acc. to Pasini and Halmi).

\section{RESULTS}

Phallodrilus leukodermatus lacks mouth and anus. There are neither traces of a gut nor even of tissues referable to an intestinal function (Figs. 1 and 2). Although the coelomic cavity is spacious and ordinarily divided by septa, a peritoneal lining is poorly developed, so that the large and irregularly shaped sarco-plasmatic portions of the longitudinal muscle cells seem to protrude directly into the coelome (Fig. 8). The massive nerve cord, ventrally embedded in cells of connective tissue(?) with large nuclei, is enclosed in a muscular sheath from which extend muscle strands towards the central parts of the coelomic cavity, where they merge in 1 to 3 longitudinal and oblique muscle fibres. They are accompanied by 1 to 2 large central blood vessels and eventually seem to fuse with the dermal musculature. A large dorsal, ventral and subneural vessel, characteristic of most oligochaetes, is completely lacking. These central structures are embedded in a mass of voluminous, 


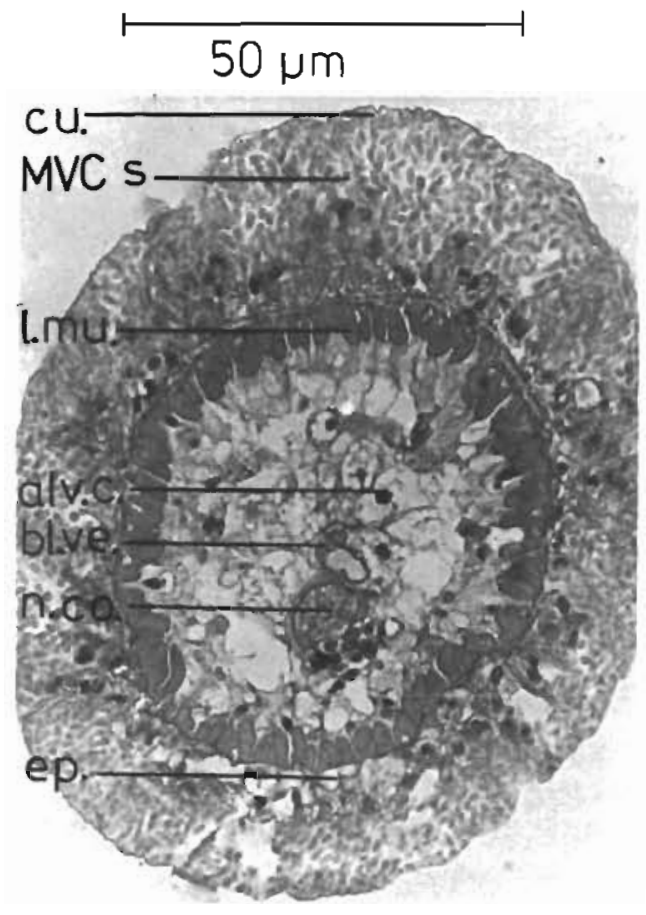

Fig. 1 phallodrilus leukodermatus. Cross-section through postclitellar region alv. c.: alveolate cells in coelomic cavity; bl. ve.: blood vessel; cu.: cuticle; ep.: epidermus; mu.: longitudinal muscles; MVCs: multi-vesiculate corpuscles; n. co.: nerve cord. Light microscope

alveolate cells contajning conspicuous nuclei and many mitochondria. The homology and function of this reticulate tissue (modified chloragogue cells?) has yet to be clarified. Sometimes, the tissue fills the whole body cavity which then assumes an almost 'mesenchymatous' appearance (Fig. 1); in other sections from the same specimen it forms only a central strand around the blood vessels and muscles leaving a wide, 'empty' coelomic cavity

The thick dermal-muscular layer consists of a solid inner tube of longitudinal musculature, surrounded by thin circular muscle fibres. Embedded between the distal parts of the longitudinal muscle cells are bundles, often arranged in a fairly regular sequence, which contain smaller longitudinal and oblique myofibrils with a sarcoplasm rich in mitochondria (Fig. 3). These bundles are well set off from the surrounding musculature by connective tissue.

Nephridia are completely lacking in these worms. Beside their absence and that of an enteric canal, it is the epidermis/cuticle-complex in which Phallodrilus leukodermatus shows most of the irregularities (Fig. 3). The epidermal layer is unusually thick; the cells vary considerably in shape and contain large nuclei. Epidermal extensions crossing the cuticle (microvilli) and

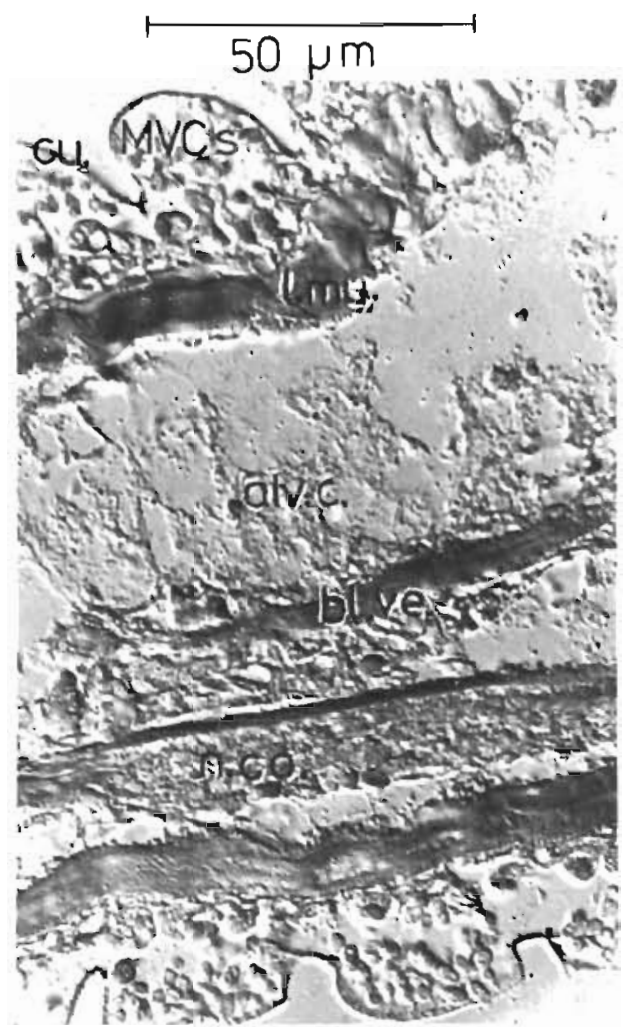

Fig. 2. Phallodrilus leukodermatus. Sagittal section through postclitellar region. For abbreviations see legend to Fig. 1. light microscope, Nomarski - contrast

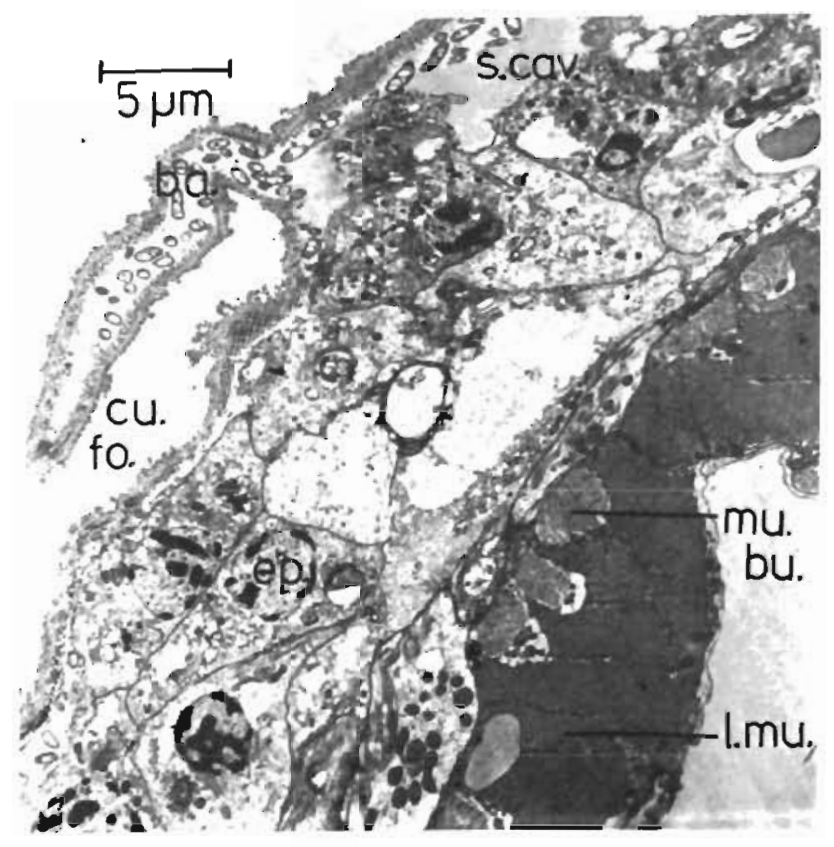

Fig. 3. Phallodrilus leukodermatus. Cross-section through anteclitellar region showing subcuticular cavity system (s. cav.) with bacteria (ba.) and cuticular fold (cu. fo.); mu. bu. muscle bundle. For further abbrevations see legend to Fig. 1 Transmission electron microscope 
ending in 'epicuticular projections' (Richards, 1977) are not found as often in the sections as in other annelids (Storch and Welsch, 1970; Rieger and Rieger, 1976; Westheide and Rieger, 1978). The basal layer of the cuticular matrix, containing loose circular fibres, is less conspicuous than the typical system of orthogonally crossing collagen fibres. The epicuticle is densely stud by countless small projections $(\approx 100 \mathrm{~nm}$ long, $\approx$ $30 \mathrm{~nm}$ wide, centre-to-centre distance $\approx 70 \mathrm{~nm}$ ) which give the surface of the worm a roughened or dotted appearance (Figs. 4, 5). The cuticle, of even thickness throughout the body's length, is intensely wrinkled exhibiting an irregular pattern of ridges - a surface structure certainly not due to fixation shrinkage (Fig. 4). In addition, the cuticle often forms narrow 'canals' and deep folds (Fig. 1). The apical membrane of the epidermal cells does not follow this complex pattern of small ridges, larger folds and elevations; hence the cuticle/epidermis interface exhibits a large 'cavitysystem'. Consequently, in wide areas of the worm's surface, the epicuticular projections seem to have lost their original contact to the apical epidermis.

This subcuticular space, relatively narrow in anteclitellar and clitellar regions, was found to harbour numerous rod-shaped cells of a structure typical for gram-negative bacteria (maximal length $\approx 1,9 \mu \mathrm{m}$, width $\approx 0,4 \mu \mathrm{m}$, but often smaller; Fig. 5). Their bacterial nature is proven by (1) the presence of a typical diffuse reticulum of DNA threads and absence of a distinct nucleus, and (2) by the double-structure of the cell wall: the outer limiting membrane which represents the cell wall proper is separated from an inner cytoplasmatic membrane by an amorphous zone. Only

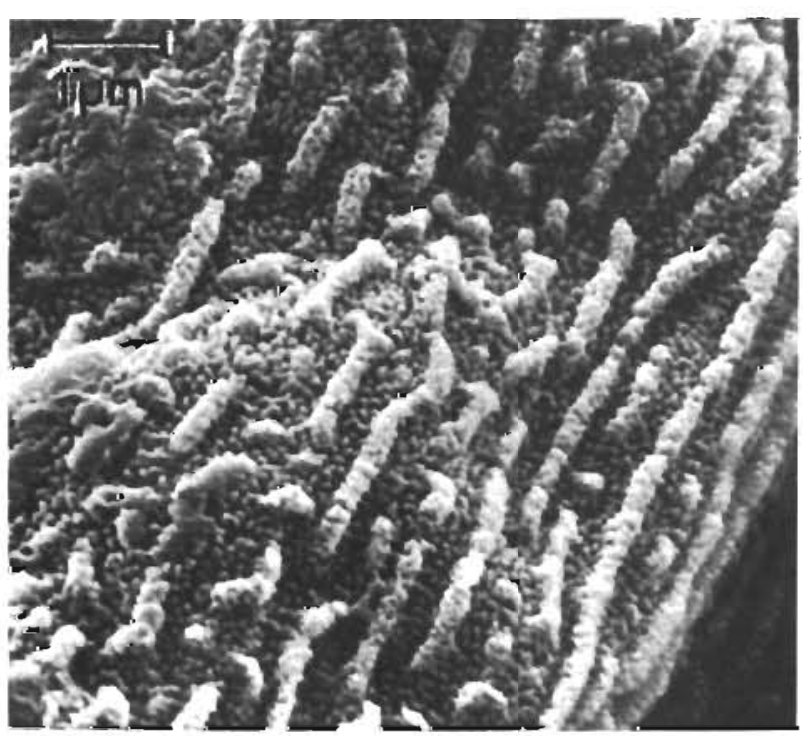

Fig. 4. Phallodrilus leukodermatus. Cuticle with dense cover of epicuticular projections and numerous irregular ridges. Scanning electron microscope very occasionally, 2 laminar subunits could be resolved in the outer cell wall. The lucent globules in the plasma of many bacteria may be reserve material.

These procaryotic cells, definitely not embedded in the cuticular matrix or epidermal plasma, are quite irregularly distributed along the worm's length. In

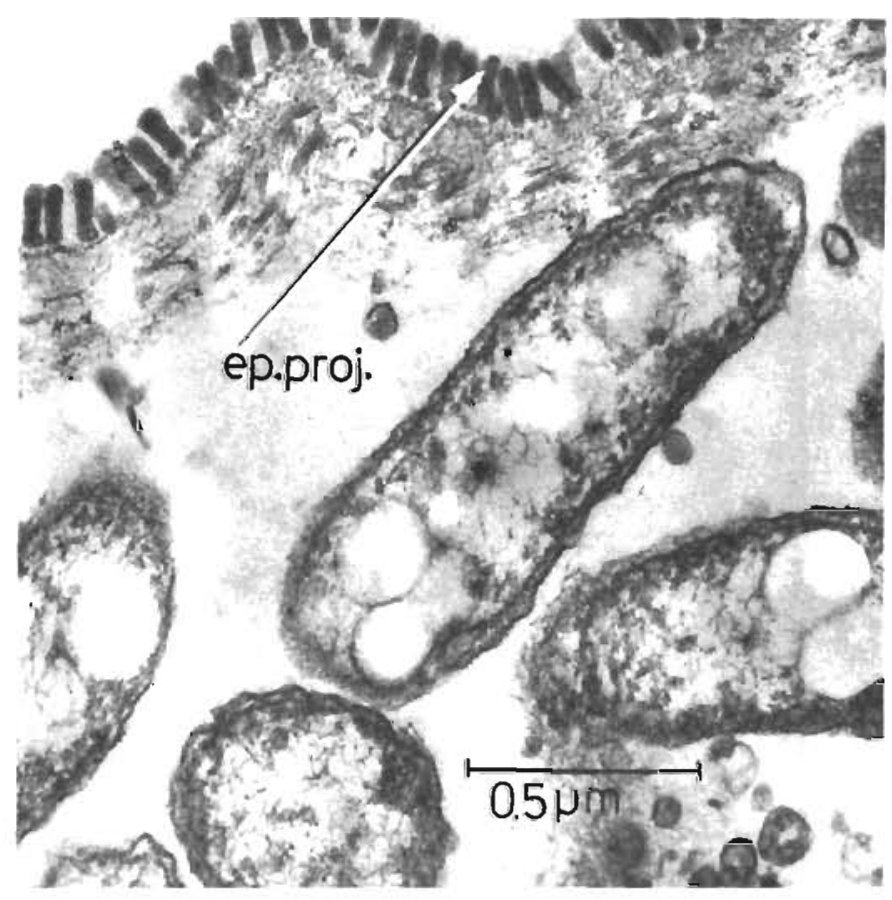

Fig. 5. Sections through bacteria underneath the cuticle of Phallodrilus leukodermatus showing their double membra. nate' cell wall and the bacterial plasma with lucent globules and diffuse chromatin threads. Ep. proj.: epicuticular projec. tions. Transmission electron microscope

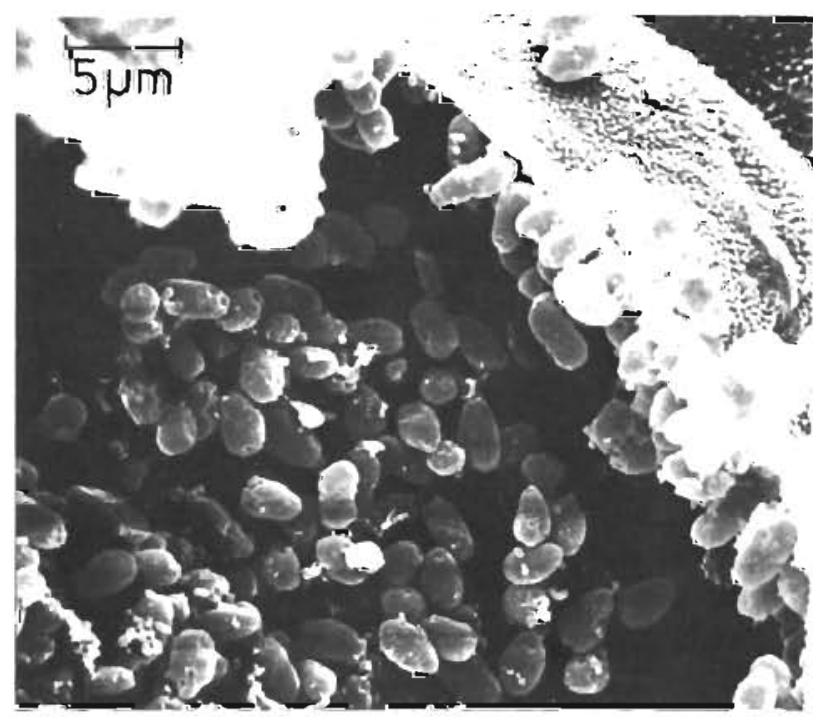

Fig. 6. Phallodrilus leukodermatus. Cuticle broken open in postclitellar segment. Subcuticular cavities filled with multivesiculate corpuscles. Only few bacteria visible. Scanning electron microscope 


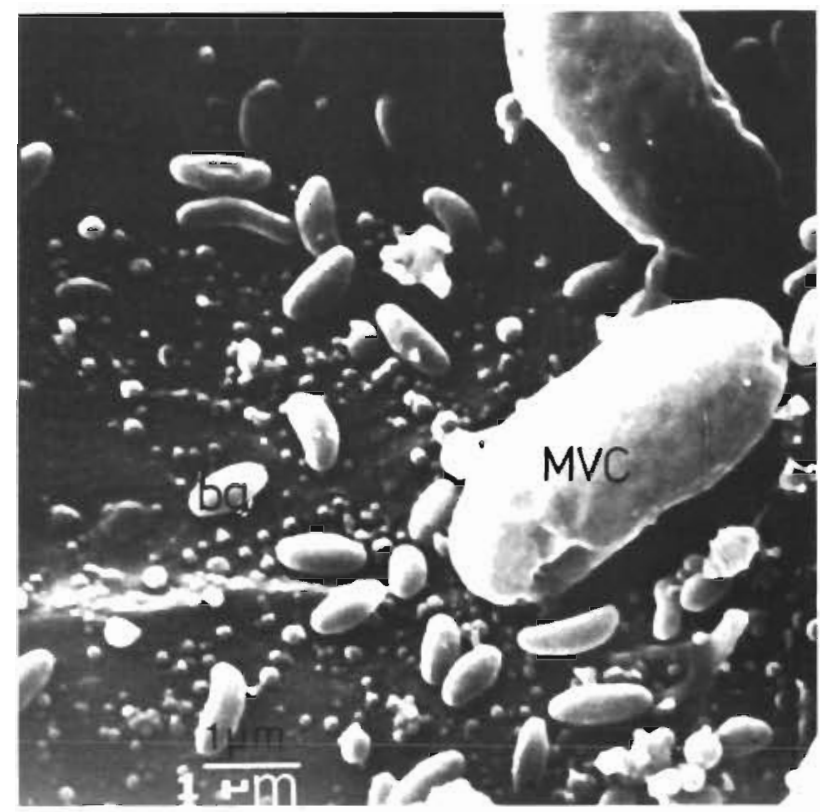

Fig. 7 Rod-shaped bacteria (ba.) and 2 multi-vesiculate corpuscles (MVC). From subcuticular cavity system in postclitellar segment of Phallodrilus leukodermatus. Scanning electron microscope

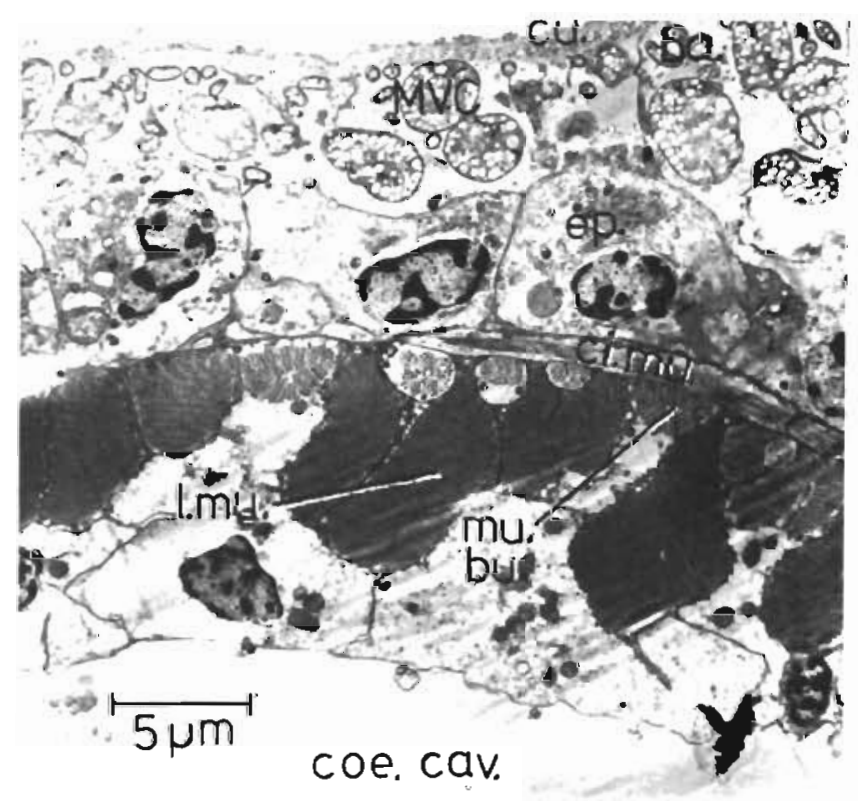

Fig. 8. Phallodrilus leukodermatus. Cross-section through postclitellar segment showing numerous multi-vesiculate corpuscles (MVC) and some bacteria (ba.) in the wide subcuticular cavity system; ci. mu.: circular muscles; coe. cav. coe'Inmic cavity. For other abbrevations see legend to Fig. 1

Transmission electron microscope

areas where the cuticle closely lines the epidermis, only few bacteria may be encountered; in wider subcuticular cavities, they form fairly dense aggregations, and are particularly frequent in the large cuticular folds (Fig. 3). However, they are mostly located as a distal layer in close vicinity to the cuticle (Fig. 8). Both juvenile and mature worms contain bacteria. The mechanism of bacterial 'infection' is as yet unknown.

Particularly in the postclitellar segments, where the subcuticular cavity system becomes very wide, it always contains - in addition to the more distal bacteria - abundant, membrane-bound, oval bodies of considerable size (length $\approx 3,2 \mu \mathrm{m}$; width $\approx 2 \mu \mathrm{m}$ ); these can densely cover the epidermis and form a thick mantle around it (Fig. 6). Tangential ultra-sections show that some of them are fully 'embedded' between the epidermal cells; most others lie completely free in the subcuticular space (Fig. 7,8). With their simple membrane enclosing a plasmatic core without any nucleus or other typical cell organelles (mitochondria, Golgi-fields), but with numerous lucent or also dark vesicles, they resemble somewhat of the 'spotted vesicles' in lipid tissues of some pogonophorans (Gupta and Little, 1970). Presently lack of information forbids further speculation on the origin, nature and function of these corpuscles.

\section{DISCUSSION}

The 'invention' of new nutritional pathways, concurrent with the reduction of the gut assumably accounts for the strange formation of the meshy tissue traversing the coelomic cavity, the loss of nephridia, the aberrant blood vessel system and the extracellular incorporation of bacteria. The fact that these micro-organisms, yet of uncertain taxonomic identity, appear to be well integrated as a distinct 'layer' in the anatomical pattern of the tubificids, speaks for a regular trophic interaction rather than a loose 'association'. Since the bacterial cells are located peripherically underneath the cuticle, one is tempted to assume a metabolic relation to photo-autotrophic procaryotes, so frequent in marine invertebrates. But this is improbable since respiratory pigments would be discernible by specific colouration of the dense bacterial aggregations. Moreover, inter-cytoplasmatic membranes, characteristic of some photo-autotrophic bacteria groups, seem to be absent here.

There remains the possibility that heterotrophic or chemo-autotrophic bacteria, using the $\mathrm{CO}_{2}$-production of the annelids, act as intermediaries in the nutritional needs of the worms by taking up dissolved organic compounds and producing substances reguired for the metabolism of their tubificid partners. There is little evidence for a direct uptake of bacteria as particulate matter by 'external digestion' through the epidermal cells, although typical 'finger-print-like' structures of decaying organelles could be regularly observed in the 
epidermis. The pathways mediated by the bacteria of phallodrilus leukodermatus and the extent to which the worms rely on non-bacterial trans-epidermal adsorption remain to be determined.

The large body surface area - not only resulting from the high length/width ratio (often 150/1), but also from abundant ridges and folds of the cuticle and countless epicuticular projections $(\approx 10$ over a distance of 0,5 $\mu \mathrm{m}$, increase in surface area roughly by ten times) favours the uptake of dissolved organic molecules. In fact, the interspaces between adjacent projections $(\approx$ $40 \mathrm{~nm}$ ) are well suited for adsorption processes. However, in view of the unusually loose contact between cuticle and epidermis through the cavity system, the effectivity of active trans-epidermal uptake of dissolved compounds may be limited.

Either by absorption of dissolved substances or by uptake of particulate matter, participation of procaryotes has been taken into consideration also for gutless pogonophorans (Gupta and Little, 1970; Southward et al., 1979; Southward and Southward, 1980), and has recently been proven for gutless Vestimentifera and giant 'white clams' from thermal vents and for the bivalve Solemya with its much reduced gut (Cavanaugh, 1980). It is noticeable that all these forms live in or close to sulphide-rich anoxic or oligoxic sediments and probably posess specific metabolic pathways for sulphide oxidation. Referring to the unusually dense populations of Phallodrilus leukodermatus, the surface horizon of their habitat was oxygenated; however tentative observations indicated rich sulphide formation to occur already below $10 \mathrm{~cm}$ depth, so that the actively crawling, relatively long worms could easily establish contact with these layers. In the laboratory, $P$. leukodermatus survived for days in anoxic environments strongly smelling of hydrogen sulphide (e.g. old sediment samples from the original habitat). Such high resistance to $\mathrm{H}_{2} \mathrm{~S}$ is, so far, unknown for interstitial annelids. Possible detoxification or adaptation systems in $P$. leukodermatus (compare Powell et al. 1979,1980 ) remain to be studied, as well as the question whether the multivesiculate cor- puscles (MVC) represent a specific adaption to the habitat or to the mode of nutrition.

Acknowledgements. I thank Mrs. M. Brumm, Dr. D. Keyser, Dr. H. Harms, all from Hamburg University and especially Dr K. Sylvia Richards, University of Keele, England for help and valuable discussions. Financial support from 'Deutsche Forschungsgemeinschaft' (Gi 100/5) is gratefully acknowledged. Contribution No. 879, Bermuda Biological Station, USA.

\section{LITERATURE CITED}

Cavanaugh, C. M. (1980). Symbiosis of chemoautotrophic bacteria and marine invertebrates. Biol. Bull. mar. biol. Lab., Woods Hole 159: 457

Giere, O. (1979). Studies on marine Oligochaeta from Bermuda, with emphasis on new Phallodrilus-species (Tubificidae). Cah. Biol mar. 20: 301-314

Gupta, B. L., Little, C. (1970). Studies on Pogonophora. 4. Fine structure of the cuticle and epidermis. Tissue and Cell 2; 637-696

Powell, E. N., Crenshaw, M. A., Rieger, R. (1979). Adaptations to sulfide in the meiofauna of the sulfide system. I. ${ }^{35} \mathrm{~S}$ sulfide accumulation and the presence of a sulfide detoxification system. J. exp. mar. Biol. Ecol. 3: 57-76

Powell, E. N., Crenshaw, M. A., Rieger, R. (1980). Adaptations to sulfide in sulfide-system meiofauna. Endproducts of sulfide detoxification in three turbellarians and a gastrotrich. Mar Ecol. Prog. Ser. 2: 169-177

Richards, K. S. (1977). Structure and function in the oligochaete epidermis (Annelida). Symp. zool. Soc. Lond. 39: 171-193

Rieger, R. M., Rieger, G. E. (1976). Fine structure of the archiannelid cuticle and remarks on the evolution of the cuticle within the Spiralia. Acta zool, Stockh. 57: 53-68

Southward, A. J., Southward, E. C. (1980). The significance of dissolved organic compounds in the nutrition of Siboglinum ekmani and other small species of Pogonophora. J. mar biol. Ass. U. K. 60: 1005-1034

Southward, A. J., Southward, E. C., Brattegard, T., Bakke, 'T (1979). Further experiments on the value of dissolved organic matter as food for Siboglinum fiordicum (Pogonophora). J. mar biol. Ass. U. K. 59: 133-148

Storch, V., Welsch, U. (1970). Über die Feinstruktur der Polychaeten-Epidermis (Annelida). Z. Morph. Tiere 66: 310-322

Westheide, W., Rieger, R. M. (1978). Cuticle ultrastructure of hesionid polychaetes (Annelida). Zoomorphologie 91: $1-18$ 